\title{
Effect of Surface Roughness on the Determination of the Creep Properties of Material by Using Three Points Bending Creep Test

\author{
Shifeng Wen ${ }^{1} \mathrm{a}^{\star}$, Sibo Zhou ${ }^{1}$, Xianglei Liu ${ }^{1}$ \\ ${ }^{1}$ Department of Engineering Mechanics, Northwestern Polytechnical University, \\ Xi'an 710072, PR China \\ awenshifeng@nwpu.edu.cn
}

Keywords: Surface roughness, Creep properties, Bending creep test, Finite element method

\begin{abstract}
The purpose of this paper is to understand the effect of surface roughness of the specimen on obtaining the creep characteristics by using bending creep tests. To this aim, a numerical study has been performed on the creep damage development of the specimen by implementing the different surface roughness into finite element models. The work may shed some light on the influence of different surface roughness on the stress distribution, the net section stress, and the indentation creep stress index were analyzed.
\end{abstract}

\section{Introduction}

There is a continued trend towards the progressive use of higher temperatures to achieve improved efficiencies in, for example, electric power generation equipment, gas turbines and chemical reactors in the last decades. This trend is resulting in an increased need for more reliable lifetime prediction methods for components subjected to creep loading [1-6]. A typical creep curve can conveniently be divided into three stages: primary creep stage, secondary or steady state creep stage and tertiary creep stage. For the engineering application, the secondary stage has been widely studied for its steady state creep rate merits, which is often possible to express creep strain rate, $\dot{\varepsilon}(t)$, in the form [1]:

$$
\dot{\varepsilon}(t)=A(T) \sigma^{n}=B \sigma^{n} \exp \left(\frac{-Q}{R T}\right)
$$

where, $\sigma$ is the stress, $\mathrm{Q}$ is the activation energy for creep deformation; $\mathrm{n}$ is stress exponent, and $\mathrm{B}$ is the creep constant. $\mathrm{R}$ is the gas constant and $\mathrm{T}$ is the absolute temperature.

Ref [12] has initially studied the creep deformation and the steady-state deflection rate of the three points bending creep of the specimen is shown as follows:

$$
\dot{d}_{s}=N \cdot P^{m}
$$

In general, the standard technique to obtain creep parameters such as $\mathrm{n}$ and $\mathrm{B}$ as well as $\mathrm{Q}$ in Eq. (1) is uniaxial tensile creep testing. This method is very conventional for the testing temperature below $1100^{\circ} \mathrm{C}$. But for the present technology, tensile creep testing is very difficult for higher temperature, such as at $1400^{\circ} \mathrm{C}$. The difficulties come not only from the limitation of specimen size ( for the reason of materials), but also from the clamps (for it is difficult to get the materials for the clamps in such high temperature). As an alternative testing method, bending creep test has been attracted for its simple in specimen and loading fixture. For example, Hollenberg et al. analyzed the relationships of creep strain, strain rate and applied stress for a ceramic material under bending creep. Based on the results of Hollenberg et al, Chuang, Krause and Chuang [7] and Chen and Chuang [8] investigated the relationships among neutral axis position, creep parameters and the bending moment. Recently, Chuang et al. [11] proposed multi-axial constitutive equations in a power-law creep form based on asymmetric creep responses under uniaxial creep. In addition, some other researchers have also studied the high temperature materials creep properties using the bending creep test by the finite element method or combining the test with numerical technique such as Lin et al [9], Ivankovic et al 
[10], Lim et al [11], Dusza et al [12] and so on. But the usual bending creep fixture in use is three-point bending test fixture or four-point bending test fixture [8-14]. However, theses fixtures are relative complex. Recently, a simpler bending creep texts fixture is designed, as shown in Fig. 1 [13, $15]$.

Bobji and Biswas [16] demonstrated via computational simulations that surface-roughness has a significant effect on hardness by using indentation method. Gerberich et al. [17] divided the work done by an applied indentation force into surface work and volume work and included the surface-roughness effect in the surface work. In this paper, we would like to understand the infulence of the suface roughness on the obtaining of the creep parameters by bending creep test.

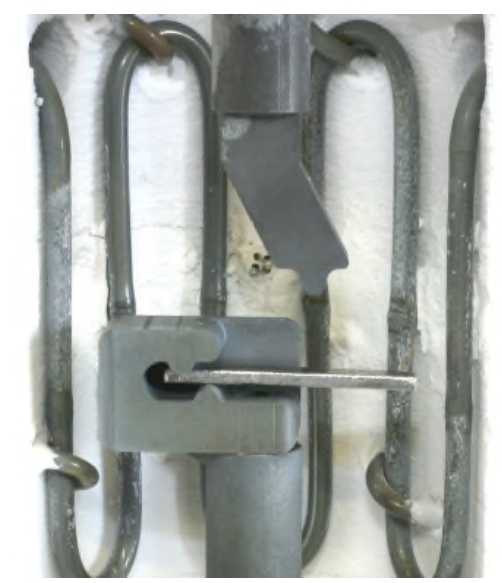

Fig. 1 The bending creep test fixture.

\section{Finite Element Model}

Using a simplified two-dimensional finite element model to simulate the creep process of bending creep test. And the surface state of the cosine form is used to display the irregular surface of the specimen. The surface roughness can be quantified as the following form $[18,19]$.

$$
R_{a}=\frac{1}{l} \int_{0}^{l}|y(x)| d x
$$

where, $y(x)$ is the distance from surface appearance to the center line, $l$ is the length of the model. In order to simulate the different surface states, the amplitude of the cosine wave amplitude is realized, they are $R_{a}=0 \mu \mathrm{m}, 6.4 \mu \mathrm{m}, 12.7 \mu \mathrm{m}$ and $25.5 \mu \mathrm{m}$. The materials used in the calculation are structural steel, its mechanical parameters for the young's modulus is $E=138 \mathrm{GPa}$, Poisson's ratio is $\mu=0.3$, its creep constant and the stress exponent is $B=1.7826 \mathrm{E}-16$ and $n=5$ [20], respectively.

Considering the surface roughness of indentation bending creep test, we use the corresponding finite element simulation to further explore the surface roughness of indentation bending creep test to determine the effects of creep parameters. Surface features of the real specimen are simulated using the surface features of the cosine form. Sketch of surface shape and mesh generation are shown in Fig. 2 .
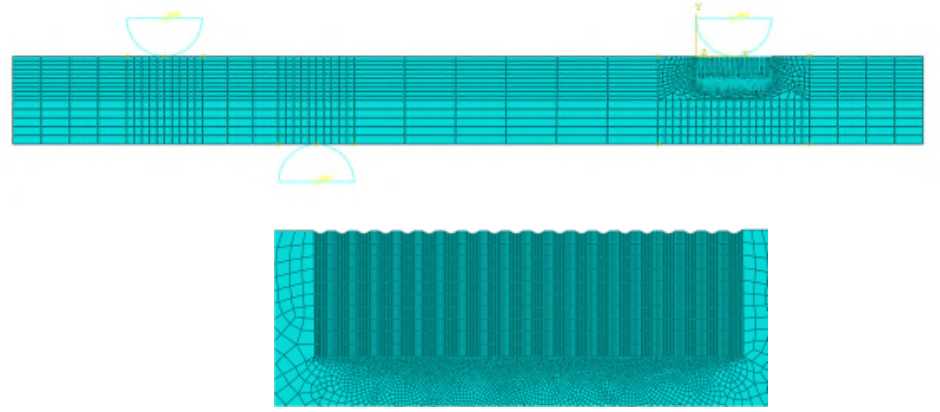

Fig. 2 Overall finite element mesh and surface schematic. 


\section{The Results of Finite Element Analysis and Discussion}

Fig. 3 shows the distribution of the Von Mises stress with the case of three different surface roughness $\left(R_{a}=6.4 \mu \mathrm{m}\right.$ (a), $12.7 \mu \mathrm{m}$ (b) and $25.5 \mu \mathrm{m}$ (c)) during the same creep time. It shows that First, the stress concentration area is below the head. Second, the larger the surface roughness, the smaller the contact area between the head and the specimen, the net stress of the corresponding specimen section will increase, that is, the maximum Von Mises stress increases with the increase of surface roughness.

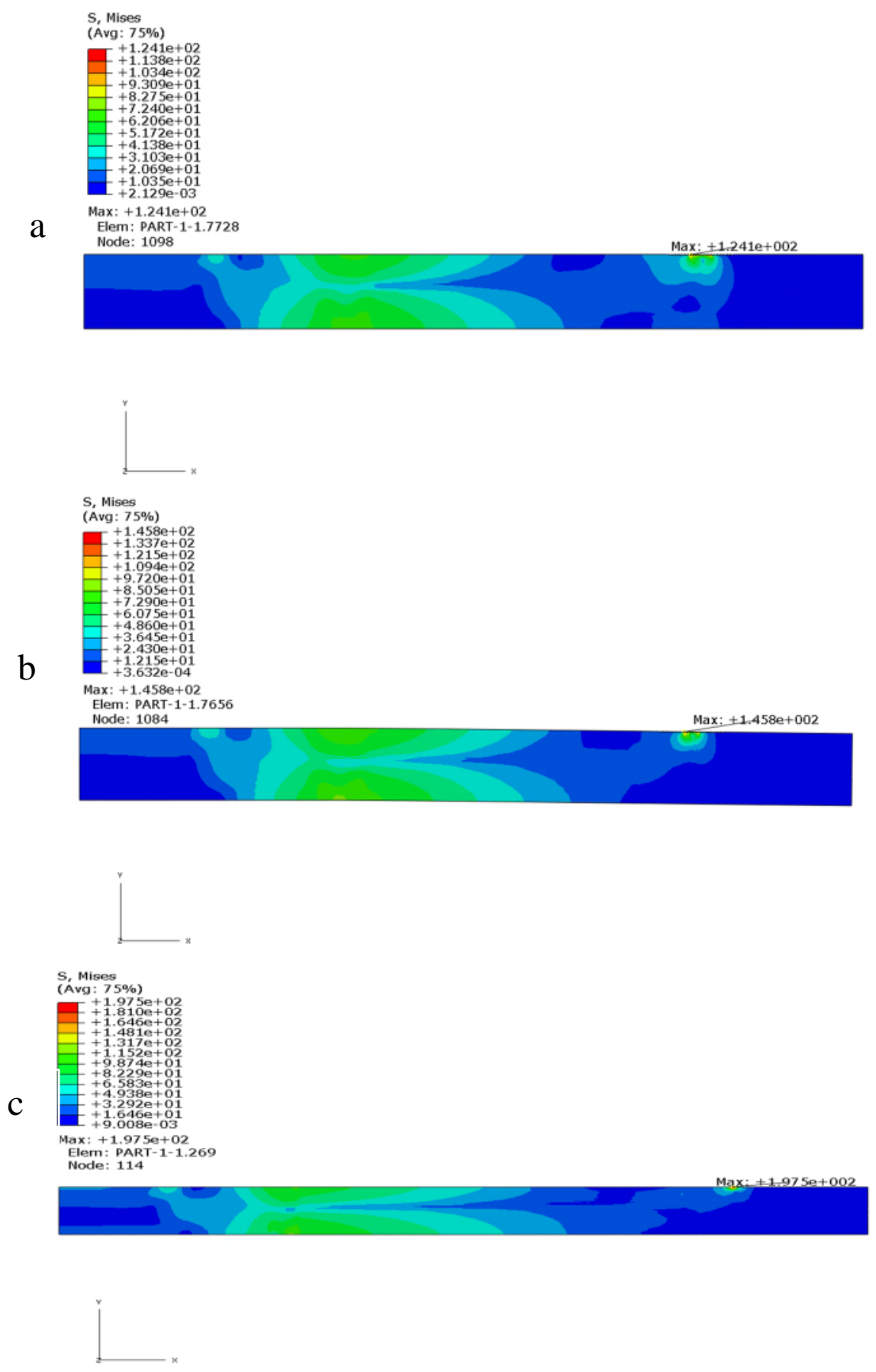

Fig. 3 The influence of different surface roughness on the distruction of the Von Mises stress (a) $\mathrm{Ra}=0 \mu \mathrm{m}$, (b) $\mathrm{Ra}=6.4 \mu \mathrm{m}$, (c) $\mathrm{Ra}=12.7 \mu \mathrm{m}$., $\mathrm{P}=60 \mathrm{MPa}, \mathrm{t}=4 \times 104 \mathrm{~s}$.

\section{Effect of Surface Roughness on the Net Stress of Cross Section}

As is known to all, at the beginning of the tensile creep, stress redistribution. Similar to the beginning of the indentation bending creep, the pressure head at the bottom of the Mises stress is also 
redistribution. This provides a theoretical basis for obtaining the creep parameters of the material by indentation creep method. In this case, the Mises stress of the joint of the pressure head is studied. In the whole process of bending creep, the node at the bottom of pressure head is always kept in contact with the pressure head. The stress size of this node can be approximated by representing the size of the net stress during the creep process. This node in different surface roughness and the pressure head load $P=60 \mathrm{Mpa}, P=250 \mathrm{MPa}$, the stress distribution of Mises is shown in Fig. 4 (a) and 4 (b). When $R_{a}=0$ indicates that the surface of the test piece is smooth.

Fig. 4 shows three important features. First, the instantaneous phase, during the initial loading stage, the cross section of contact area is very small, which leads to the stress concentration resulting in a dramatic increase in damage (as shown in Fig. 3). The greater the surface roughness $R_{a}$, the stress concentration is more serious. However, the phenomenon of stress concentration will not last for a long time, because the damage promotes the stamping speed, which leads to the increase of contact area. So the net section stress decreases rapidly with the increase of damage. Second, the net section stress decreases with the creep time and eventually tends to a stable value. The main reason that leads to this phenomenon is that, with the increase of the damage, the contact area increases and eventually tends to be flat. It is worth noting that, although the creep time of Fig. 4 (b) and Fig. 4(a) is the same, but because of the pressure head load is bigger, so resulting in a more stable damage values in Fig. 4(b). It is also indicated that the pressure head load is an important factor to eliminate the surface roughness. Third, when the pressure head load is $60 \mathrm{MPa}$, the influence that the net stress of section is affected by the surface roughness is more sensitive, and the greater the surface roughness, the greater the net cross section. This is because the pressure head load is too small to flatten specimen surface, then the surface roughness on the cross section plays a decisive role on the size of the net stress.
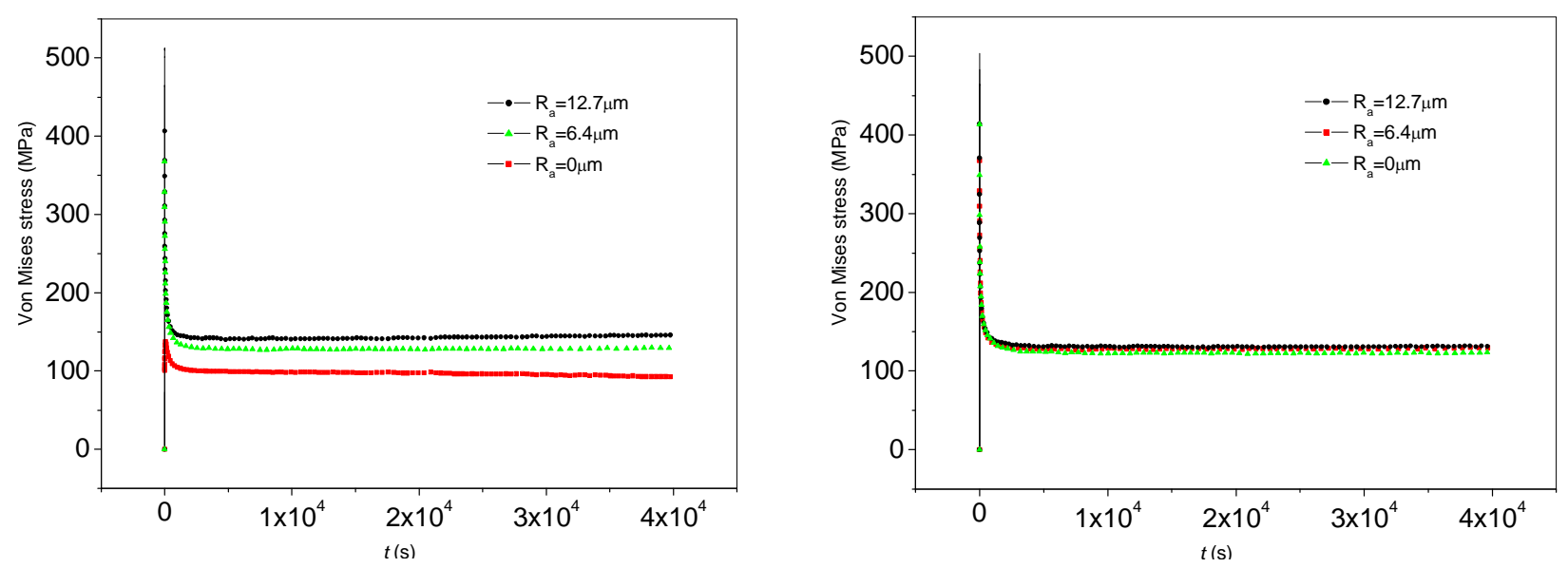

Fig. 4 The influence of the different surface roughness on the development of the Von Mises stress (a) $\mathrm{P}=60 \mathrm{MPa}$, (b) $\mathrm{P}=200 \mathrm{Mpa}$.

\section{Effect of Surface Roughness on Deflection and Deflection Rate}

In front of the stress analysis shows that the pressure head load for $P=200 \mathrm{MPa}$, the influence of surface roughness for deflection rate $\dot{d}$ is very weak, but when the pressure head load is $P=60 \mathrm{MPa}$, the influence of surface roughness on the depth of indentation $\dot{d}$ is very obvious.

In the case of different surface roughness and the same pressure head load $P=60 \mathrm{MPa}$, the relationship between the indentation deflection and creep time is shown in Fig. 5 (a), as can be seen from the figure, the deflection increases with the increase of surface roughness. This is because the damage degree increases with the increase of the surface roughness in the same creep time. In the case of relatively small loads, the first and second creep stages occupy the whole process of indentation bending creep. The creep deflection curves of creep time are composed of a series of line segments. The cause of this phenomenon is that the pressure head load is too small to flatten the surface roughness of specimens. Due to the accumulation of damage, section contact area increases, this also leads to the increase of the static stress $\sigma_{N}$ of the section. 
Fig. 5 (b) shows the process that indentation deflection rate with the creep time eventually reaches a stable value in the case of different surface roughness. It is assumed that when the creep time is $t \rightarrow$ $\infty$, the pressure head and the specimen surface are in a state of full contact. At this time, the deflection rate tends to be a stable value, which is similar to the results obtained when the surface is smooth.
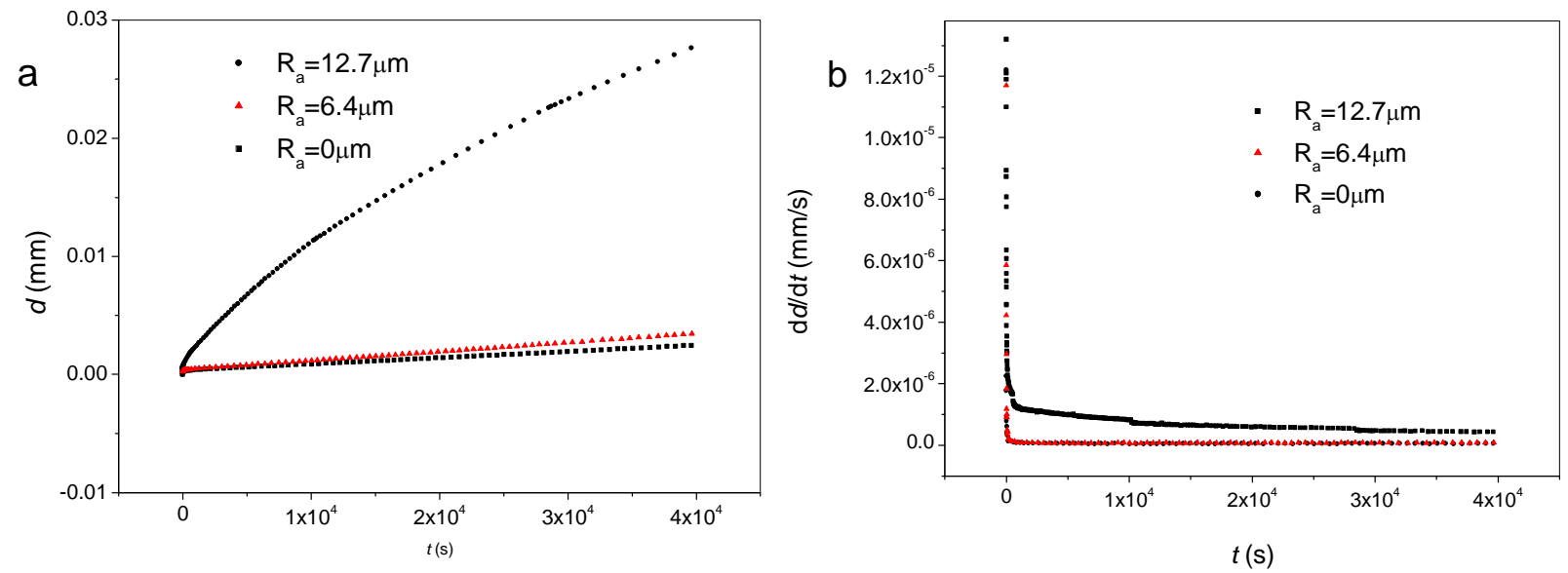

Fig. 5 The influence of the different surface roughness on the

(a) the deflection (b) the steady- state creep deflection $\mathrm{P}=60 \mathrm{MPa}$.

\section{Effect of Surface Roughness on Determining Indentation Creep Stress Exponent}

By the formula (2), the slope of the $\lg \dot{d}-\lg P$ curve is the indentation creep stress index. For finite element calculation, the same numerical simulation is used to study the influence of surface roughness on the bending creep index, and three different surface roughness's $R_{a}=0,6.4,12.7$ and different pressure head load $P=30 \mathrm{MPa}, 60 \mathrm{MPa}, 100 \mathrm{MPa}, 150 \mathrm{MPa}, 200 \mathrm{MPa}, 250 \mathrm{MPa}$ were researched. The final size of deflection rate is obtained by the finite element method. The variation tendency of indentation bending creep exponent, i.e. $\lg \dot{d}-\lg P$ curve, can be observed from the Fig. 6.

Fig. 6 shows that when the pressure head load is greater than $150 \mathrm{MPa}$, the size of the bending creep exponent and the size of the finite element calculation of the theoretical value are approximately equal. This shows that the influence of surface roughness of specimen on indentation creeps will be reduced or even negligible when the pressure head is larger than a fixed value.

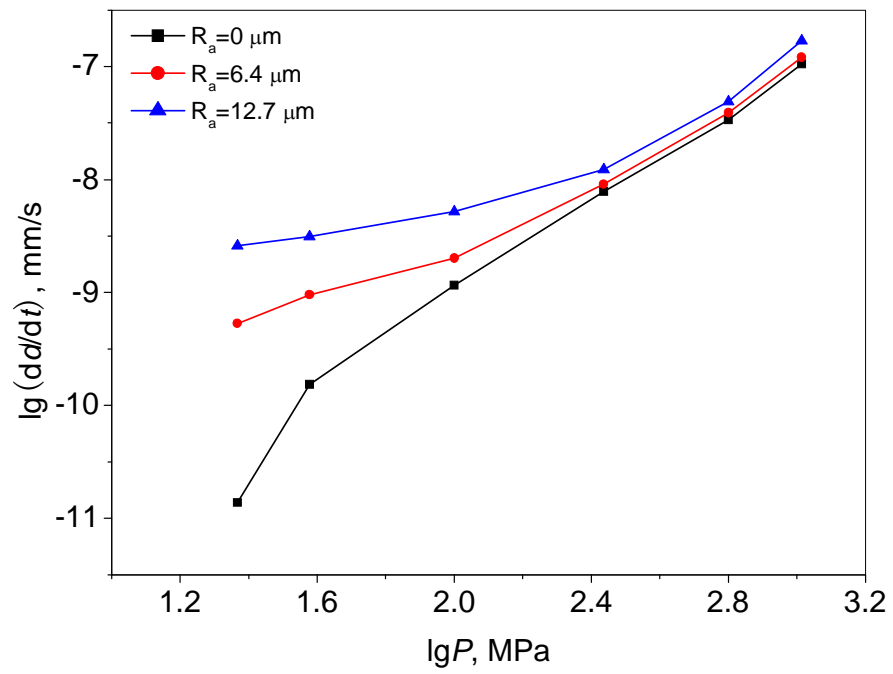

Fig. 6 The influence of different of the surface roughness on the creep stress exponent.

On the contrary, when the pressure head is less than $150 \mathrm{MPa}$, the influence of the surface roughness of the specimen on the indentation creep index is very significant. And the creep stress 
exponent obtained is also smaller than the theoretical value. The cause of this phenomenon can be attributed to the following points: First, when the pressure head load is smaller, the contact area between the pressure head and the specimen increases with the increase of damage. At this point, the surface roughness Play a regulatory role on cross-section static stress. Second, a relatively large load (load is still less than $150 \mathrm{MPa}$ ), will produce the corresponding large damage degree. Therefore, the sharp increase in the contact area leads to a sharp decrease in the cross-section static stress. Finally, in the range of small load, the speed of pressure head is very sensitive to the change of load due to the adjustment of the surface roughness. And this eventually leads to the creep stress exponent small. The larger the surface roughness, the more obvious this regulation effect. The creep stress exponent obtained will be smaller until the effect is lost.

\section{Summary}

Through a numerical investigation, the effect of surface roughness on the bending creep behaviour is analyzed in the present paper. A simplified creep damage model is proposed and combined with the bending creep model of ref. [10]. Analytical results show that when the pressure head load is $80 \mathrm{MPa}$, the surface of the specimen tend to be flattened, then the effect of surface roughness on the damage will be reduced and eventually even negligible. When the creep time is $t \rightarrow \infty$, the pressure head and the specimen surface are in a state of full contact. At this time, the deflection rate tends to be a stable value, which is similar to the results obtained when the surface is smooth. The variation tendency of indentation bending creep exponent, i.e. $\lg \dot{d}-\lg P$ curve, can be observed from the Fig. 3 . when the pressure head load is greater than $150 \mathrm{MPa}$, the size of the bending creep exponent and the size of the finite element calculation of the theoretical value are approximately equal. This shows that the influence of surface roughness of specimen on indentation creeps will be reduced or even negligible when the pressure head is larger than a fixed value.

\section{References}

[1] G. A. Webster and R. A. Ainsworth. High Temperature component Life Assessment. Chapman \& Hall, London, UK.

[2] D. H. Sastry. Impression creep technique-An overview. Mater. Sci. Eng. A 409 (2005) 67.

[3] James C. M. Li. Impression creep and other localized tests. Mater. Sci. Eng. A 322 (2002) 23-42.

[4] D. Dorothee, R. Klaus, S. Bridit, etc. Creep of a TiAl alloy: a comparison of indentation and tensile testing. Mater. Sci. Eng. A 357 (2003) 346-354.

[5] Z. F. Yue, B. Stockhert, G. Eggeler. A creep finite element analysis of indentation creep testing in two phase microstructures (particle/matrix-and thin film/substrate-systems). Comput. Mater. Sci. 21 (2001) 37.

[6] T. H. Hyde. K. A. Yehia, A. A. Becker. Application of the reference stress method for interpreting impression creep test date. Mater. High Temp. 13(3) (1995) 133.

[7] R. F. Krause, T. J. Chuang (eds. ), Ceramic Today-Tr morrow's Ceramics. Elsevier, 1991, pp. 1865.

[8] C. F. Chen, T. J. Chuang, Improved Analysis for Flexural Creep with Application to Sialon Ceramics J. Am. Ceram. Sot. Z (8) (1990) 2366.

[9] T. J. Chuang, S. M. Wiederhorn, Damage-Enhanced Creep in a Siliconized Silicon Carbide: Mechanics of Deformation D. Am. Ceram. Soc. 74(199I) 2531.

[10]M. T. Lin, J. L. Shi, D. Y. Jiang, M. L. Ruan, T. R. Lai. High temperature creep of a hot-pressed b-sialon. Mater. Sci. Eng. A300 (2001) 61. 
[11]H. Ivankovic, E. Tkalcec, R. Rein, H. Schmidt. Microstructure and high temperature 4-point bending creep of sol-gel derived mullite ceramics. J. European Ceram. Soc. 26 (2006) 1637.

[12]H. J. Lim, J. W. Jung, D. B. Han, K. T. Kim. A finite element model for asymmetric creep behavior of ceramics. Mater. Sci. Eng. A 224 (1997) 125.

[13]J. Dusza, P. Hvizdog, W. Steinkellnerm, K. Kromp. Bending creep behaviour pf pressureless sintered MoSi2, Scripta Mater. 37 (1997) 471.

[14]B. X. Xu, Z. F. Yue, G. Eggeler, A numerical procedure for retrieving material creep properties from bending creep tests. Acta Mater. 55 (2007) 6275.

[15]S. F. Wen, W. Z. Yan, X. S. Wang, J. Liu, Z. F. Yue, Prediction of the strength using by bending test method, Mater. Des. 31 (2010) 1828.

[16]M. S. Bobji, S. K. Biswas. Estimation of hardness by nanoindentation of rough surfaces J. Mater. Res. 13 (1998) 11.

[17]W. W. Gerberich, N. I. Tymiak, J. C. Grunlan, M. F. Horstemeyer, M. I. Baskes. Interpretations of Indentation Size Effects. J. Appl. Mech. (Trans ASME) 69 (2002) 433.

[18]D. Hibbit, B. Karlsson, P. Sorenson, ABAQUS standard User's Manual, Version 6. 4, USA HKS Inc., 2003.

[19]M. M. Ayob, A. Mital, Manual material handling, London: Taylor \& Francis, 1989.

[20]G. A. Webster, R. A. Ainsworth, High temperature component life assessment. Chapman \& Hall, London, 1994. 